Check for updates

Cite this: RSC Adv., 2018, 8, 14500

\title{
Effects of arbuscular mycorrhizal fungi on Leymus chinensis seedlings under salt-alkali stress and nitrogen deposition conditions: from osmotic adjustment and ion balance
}

\author{
Jixiang Lin, (DD ab Xiaoyuan Peng, ${ }^{a}$ Xiaoyu Hua, ${ }^{a}$ Shengnan Sun, ${ }^{c}$ Yingnan Wang ${ }^{a}$ \\ and Xiufeng Yan*a
}

Nitrogen deposition and soil salinization-alkalization have become major environmental problems throughout the world. Leymus chinensis is the dominant, and considered the most valuable, species for grassland restoration in the Northeast of China. However, little information exists concerning the role of arbuscular mycorrhizal fungi (AMF) in the adaptation of seedlings to the interactive effects of nitrogen and salt-alkali stress, especially from the perspective of osmotic adjustment and ion balance. Experiments were conducted in a greenhouse and Leymus chinensis seedlings were cultivated with $\mathrm{NaCl} / \mathrm{NaHCO}_{3}$ under two nitrogen treatments (different concentrations of $\mathrm{NH}_{4}{ }^{+} / \mathrm{NO}_{3}{ }^{-}$). Root colonization, seedling growth, ion content, and solute accumulation were measured. The results showed that the colonization rate and the dry weights of the seedlings were both decreased with the increasing salt-alkali concentration, and were much lower under alkali stress. Both of the nitrogen treatments decreased the colonization rate and dry weights compared with those of the AM seedlings, especially under the $\mathrm{N} 2$ (more $\mathrm{NH}_{4}{ }^{+}-\mathrm{N}$ content) treatment. The $\mathrm{Na}^{+}$content increased but the $\mathrm{K}^{+}$content decreased under salt-alkali stress, and more markedly under alkali stress. AMF colonization decreased the $\mathrm{Na}^{+}$content and increased the $\mathrm{K}^{+}$content to some extent. In addition, the nitrogen treatments had a negative effect on the two ions in the AM seedlings. Under salt stress, the seedlings accumulated abundant $\mathrm{Cl}^{-}$to maintain osmotic and ionic balance, but alkali stress inhibited the absorption of anions and the seedlings accumulated organic acids in order to resist the imbalance of both osmosis and ions, whether under the AM or nitrogen treatments. In addition, proline accumulation is thought to be a typical adaptive feature in both $A M$ and non-AM plants under nitrogen and salt-alkali stress. Our results suggest that the salt-alkali tolerance of Leymus chinensis seedlings is enhanced by association with arbuscular mycorrhizal fungi, and the seedlings can adapt to the nitrogen and salt-alkali conditions by adjusting their osmotic adjustment and ion balance. Excessive nitrogen partly decreased the saltalkali tolerance of the Leymus chinensis seedlings.

Received 24th January 2018

Accepted 23rd March 2018

DOI: $10.1039 / \mathrm{c} 8 \mathrm{ra00721g}$

rsc.li/rsc-advances increased tenfold over the past 150 years and it has been predicted to be at least twice the current level by the 2050s. ${ }^{2}$ Excess input of nitrogen can have adverse ecological effects, such as changes in soil function and eutrophication. ${ }^{3,4}$ Nitrogen is also a limiting resource in the grassland ecosystem of northern China, which exerts a profound effect on plant and soil microorganisms. $^{5}$ In addition, not only is the total $\mathrm{N}$ content increasing, but the ratio of $\mathrm{NH}_{4}{ }^{+}-\mathrm{N}$ to $\mathrm{NO}_{3}{ }^{-}-\mathrm{N}$ is also changing as a result of $\mathrm{N}$ deposition. However, to the best of our knowledge, the physiological effect of $\mathrm{NH}_{4}{ }^{+} / \mathrm{NO}_{3}{ }^{-}$has been always overlooked.

Salinity is considered one of the most important environmental factors limiting plant growth and yield throughout the world. ${ }^{6}$ The stress caused by soil salinity generally involves osmotic stress and ion-induced injury. ${ }^{7}$ These effects can
${ }^{a}$ Alkali Soil Natural Environmental Science Center, Northeast Forestry University, Key Laboratory of Saline-alkali Vegetation Ecology Restoration in Oil Field, Ministry of Education, Harbin, 150040, China. E-mail: xfyan@nefu.edu.cn; Fax: +86-45182192185; Tel: +86-451-82192185

${ }^{b}$ Department of Plant Pathology, North Carolina State University, Raleigh, NC, 276957716, USA

${ }^{c}$ Colleges of Animal Science and Technology, Yangzhou University, Yangzhou 225009, China 
inhibit nutrient absorption and prevent them from being transported within plants. In order to resist environmental stress, most plants have developed a variety of adaptive mechanisms, such as the synthesis of compatible solutes, the accumulation or exclusion of selected ions, and the control of ion uptake by the roots. ${ }^{8}$ In addition, soil alkalization is also a marked feature in Northeastern China. The existence of alkali stress has been demonstrated to be more severe than salt stress due to the high $\mathrm{pH}$, which may inhibit ion uptake and disrupt ionic balance. ${ }^{9-11}$ Thus, they are actually two totally different types of stress. Yet, in spite of this, people pay little attention to the effect of alkali stress compared with that of salt stress.

Arbuscular mycorrhizal fungi (AMF), a kind of ancient soil microorganism, widely occurs in saline soil, and can form mutualistic relationships with over $80 \%$ of terrestrial plants. ${ }^{\mathbf{1 2}}$ It is known that arbuscular mycorrhiza can enhance plant growth and development, and can also alleviate the adverse effects of salt stress. ${ }^{\mathbf{1 3 4}}$ The potential mechanisms for mycorrhizal plants responding to salt stress may include improving the nutrient uptake ability of the plant (especially the uptake of phosphorus), maintaining higher antioxidant enzymatic activities, elevating the $\mathrm{K}^{+}$content, and changing the root functions. ${ }^{\mathbf{1 5 - 1 7}}$ However, the ecological role of arbuscular mycorrhizal fungi on the osmotic adjustment and ion transport of plants under alkali stress (high pH), especially the interactive effects of alkali stress and nitrogen deposition (different concentrations of $\mathrm{NH}_{4}{ }^{+}$/ $\mathrm{NO}_{3}{ }^{-}$) conditions, has still rarely been reported.

Leymus chinensis, also called alkali grass, is a perennial rhizomatous species of the family Poaceae. This grass not only has a high tolerance to salt-alkali soil, but also contains quite a lot of nutrients, such as carbohydrates, minerals, and proteins. ${ }^{18}$ Thus, some reports have indicated that Leymus chinensis is considered to be one of the most valuable species for grassland restoration in the Northeast of China. ${ }^{\mathbf{1 9 , 2 0}}$ Here, we evaluated the contribution of arbuscular mycorrhizal fungi to the growth, ion content, and solute accumulation of Leymus chinensis seedlings under salt-alkali stress and nitrogen deposition. We aimed firstly to clarify the role of AMF during the adaptation of the Leymus chinensis seedlings to salt-alkali stress, and then we further explored the response of the plantAMF to salt/alkali stress and its interactive effects with nitrogen deposition (different concentrations of $\mathrm{NH}_{4}{ }^{+} / \mathrm{NO}_{3}{ }^{-}$) from the perspective of osmotic adjustment and ion balance.

\section{Materials and methods}

\section{Plant culture, inoculation, and stress treatments}

The AMF (Glomus mosseae, BGC HEB02) used for inoculation was provided by the Institute of Plant Nutrition and Resources, Beijing Academy of Agriculture and Forestry Sciences, China. A pot experiment was conducted from April to July in 2015 at Northeast Forestry University, Harbin City, Heilongjiang Province, China. A randomized block design with three factors was used in this experiment: AMF treatment (non-AMF as the control), nitrogen treatments [0 mM; $\mathrm{N} 1\left(10 \mathrm{mM} \mathrm{NH}_{4} \mathrm{NO}_{3}\right)$ and $\mathrm{N} 2\left(10 \mathrm{mM} \mathrm{NH}_{4} \mathrm{Cl}: \mathrm{NH}_{4} \mathrm{NO}_{3}=3: 1\right)$, and salt-alkali stress (0, 100 , and $200 \mathrm{mM} \mathrm{NaCl} / \mathrm{NaHCO}_{3}$ ). Each nitrogen level had +AMF or $-\mathrm{AMF}$ treatment, and each +AMF or $-\mathrm{AMF}$ treatment had salt or alkali stress treatment. The $\mathrm{pH}$ values of the salt stress were 6.28 and 6.30 , and were 10.18 and 10.39 for the alkali stress. Each treatment was conducted in 4 replicates and eight seedlings were included in each pot.

Leymus chinensis seeds were collected from the Grassland Ecosystem Field Station, Institute of Grassland Science in Northeast Normal University, Jilin Province, China $\left(123^{\circ} 44^{\prime} \mathrm{E}\right.$, $44^{\circ} 44^{\prime} \mathrm{N}$ ) in July 2013 . The seeds were firstly surface sterilized with $10 \%$ sodium hypochlorite for $10 \mathrm{~min}$, and then were sown in the plastic pots. Each pot was $15 \mathrm{~cm}$ in upper diameter, $12 \mathrm{~cm}$ in lower diameter, $15 \mathrm{~cm}$ in depth, and filled with $2 \mathrm{~kg}$ of an autoclaved soil mixture (soil : sand $3: 1, \mathrm{v} / \mathrm{v}$ ). Before this step, the substrate was autoclaved at $121^{\circ} \mathrm{C}$ and $240 \mathrm{kPa}$ pressure for $2 \mathrm{~h}$ to ensure that all possible mycorrhizal propagules and other microorganisms had been destroyed. Each pot was inoculated with either $20 \mathrm{~g}$ of the inoculant for the inoculation treatment (+AMF) or $20 \mathrm{~g}$ of sterilized inoculant for the non-inoculation treatment (-AMF). We also added $30 \mathrm{~mL}$ of filtered inoculant (through a $0.25 \mu \mathrm{m}$ filter membrane), free from mycorrhizal propagules, to the -AMF treatment to maintain the same microorganism biota. The inoculants were added $2 \mathrm{~cm}$ below the seeds. The stress treatments were carried out by adding the corresponding solutions (as described above) 120 days after sowing, and the control treatment was irrigated with $300 \mathrm{~mL}$ of distilled water. The seedlings were harvested 7 days after the treatments.

\section{Growth index and mycorrhizal colonization measurements}

The harvested seedlings were firstly washed with distilled water and then the roots and shoots were separated. The shoots were vacuum-dried at $65{ }^{\circ} \mathrm{C}$ to a constant weight and the dry weights were then determined.

For the evaluation of AMF colonization, a fraction of the roots was carefully washed, cut into $1 \mathrm{~cm}$ long segments, cleaned with $10 \% \mathrm{KOH}$ solution, and stained with $0.05 \%$ trypan blue in lactophenol. ${ }^{21}$ The AMF colonization was then quantified according to the formula described by $\mathrm{Wu}$ et al.:22

$$
\begin{gathered}
\text { AMF colonization }(\%)=(\text { root length infected/root length } \\
\text { observed }) \times 100
\end{gathered}
$$

\section{Determination of inorganic ions and organic solutes}

Dry samples of Leymus chinensis seedlings (50 mg) were treated with $10 \mathrm{~mL}$ deionized water at $100{ }^{\circ} \mathrm{C}$ for $1 \mathrm{~h}$ and the extract was taken to determine any free inorganic ions and organic acids. An atomic absorption spectrophotometer (TAS-990, Purkinje General, Beijing) was used to determine the $\mathrm{Na}^{+}, \mathrm{K}^{+}$, free $\mathrm{Mg}^{2+}$, and free $\mathrm{Ca}^{2+}$ content. The $\mathrm{NO}_{3}{ }^{-}, \mathrm{Cl}^{-}, \mathrm{H}_{2} \mathrm{PO}_{4}{ }^{-}$, and $\mathrm{SO}_{4}{ }^{2-}$ amounts were determined by ion chromatography (DX-300 ion chromatographic system; AS4A-SC ion-exchange column). For the analysis of the organic acids, measurements were also undertaken using ion chromatography (DX-300 ion chromatographic system; ICE-AS6 ion-exclusion column). The proline and total soluble sugar amounts were measured using 
ninhydrin and anthrone, respectively, according to Bao et al. ${ }^{23}$ and Zhu et al. ${ }^{24}$ Betaine was extracted with $80 \%$ methanol for $20 \mathrm{~min}$ at $70{ }^{\circ} \mathrm{C}$ and determined using the method established by Greive and Grattan. ${ }^{25}$

\section{Statistical analysis}

The data were analyzed using the statistical software SPSS 13.0 (SPSS Inc, Chicago, IL, USA). The data were subjected to an analysis of variance (one-, two- or three-way ANOVA) with the inoculation treatment, salt/alkali stress, nitrogen treatment, and their interactions as the sources of variation. Post hoc comparisons with Duncan's multiple range tests were used to identify the differences between groups with $P<0.05$ as the significance cut-off.

\section{Results and discussion}

\section{Root colonization and seedling growth}

The root mycorrhizal colonization was decreased significantly by the nitrogen treatments under salt-alkaline stress $(P<0.01)$. Without the nitrogen treatment and stress conditions, the root mycorrhizal colonization can reach a maximum value of $97 \%$. Compared to the $\mathrm{N} 1$ treatment, the colonization rate under the N2 treatment was much lower. Moreover, both salt and alkali stresses affected the mycorrhizal colonization, and the inhibition action of alkali stress was much stronger. Under the highest salinity stress concentration $(200 \mathrm{mM})$, the colonization rate reached nearly $90 \%$, but only reached $63 \%$ under alkalinity stress at the same stress intensity (Tables 1 and 2).

Table 1 Mycorrhizal colonization rate and seedling dry weight of Leymus chinensis under nitrogen deposition and salinity conditions ${ }^{a}$

\begin{tabular}{lll}
\hline Treatment & $\begin{array}{l}\text { Mycorrhizal colonization } \\
\text { rate }(\%)\end{array}$ & Dry weight (g per plant) \\
\hline $\mathrm{CK}-\mathrm{AM}$ & $0.00 \pm 0.00 \mathrm{a}$ & $0.34 \pm 0.03 \mathrm{a}$ \\
$\mathrm{CK}+\mathrm{AM}$ & $97.33 \pm 1.33 \mathrm{~d}$ & $0.49 \pm 0.03 \mathrm{~b}$ \\
$\mathrm{CK}+\mathrm{AM}+\mathrm{N} 1$ & $78.33 \pm 1.20 \mathrm{c}$ & $0.36 \pm 0.02 \mathrm{a}$ \\
$\mathrm{CK}+\mathrm{AM}+\mathrm{N} 2$ & $71.67 \pm 1.76 \mathrm{~b}$ & $0.33 \pm 0.02 \mathrm{a}$ \\
$\mathrm{S} 1-\mathrm{AM}$ & $0.00 \pm 0.00 \mathrm{a}$ & $0.27 \pm 0.01 \mathrm{a}$ \\
$\mathrm{S} 1+\mathrm{AM}$ & $92.00 \pm 1.00 \mathrm{~d}$ & $0.37 \pm 0.04 \mathrm{~b}$ \\
$\mathrm{~S} 1+\mathrm{AM}+\mathrm{N} 1$ & $69.33 \pm 0.67 \mathrm{c}$ & $0.31 \pm 0.01 \mathrm{a}$ \\
$\mathrm{S} 1+\mathrm{AM}+\mathrm{N} 2$ & $64.33 \pm 0.67 \mathrm{~b}$ & $0.28 \pm 0.01 \mathrm{a}$ \\
$\mathrm{S} 2-\mathrm{AM}$ & $0.00 \pm 0.00 \mathrm{a}$ & $0.24 \pm 0.02 \mathrm{a}$ \\
$\mathrm{S} 2+\mathrm{AM}$ & $88.67 \pm 0.67 \mathrm{~d}$ & $0.31 \pm 0.04 \mathrm{~b}$ \\
$\mathrm{~S} 2+\mathrm{AM}+\mathrm{N} 1$ & $63.67 \pm 1.33 \mathrm{c}$ & $0.29 \pm 0.02 \mathrm{~b}$ \\
$\mathrm{~S} 2+\mathrm{AM}+\mathrm{N} 2$ & $59.33 \pm 2.96 \mathrm{~b}$ & $0.28 \pm 0.02 \mathrm{ab}$ \\
$\mathrm{AM}$ & $* * *$ & $* * *$ \\
$\mathrm{~S}$ & $* * *$ & $*$ \\
$\mathrm{AM} * \mathrm{~S}$ & $* * *$ & N.S. \\
$\mathrm{N} 1$ & $* * *$ & $* *$ \\
$\mathrm{~N} 1 * \mathrm{AM}$ *S & $* * *$ & N.S. \\
$\mathrm{N} 2$ & $* * *$ & $* * *$ \\
$\mathrm{~N} 2 * A M * \mathrm{~S}$ & $\mathrm{~N} . \mathrm{S}$. & N.S.
\end{tabular}

${ }^{a}$ The different letters indicate significant differences between the treatments (Tukey's test $P<0.05$ ). ${ }^{* * *} P<0.001,{ }^{* *} P<0.01,{ }^{*} P<$ 0.05, N.S. $=$ not significant.
Table 2 Mycorrhizal colonization rate and seedling dry weight of Leymus chinensis under nitrogen deposition and alkalinity conditions ${ }^{a}$

\begin{tabular}{|c|c|c|}
\hline Treatment & $\begin{array}{l}\text { Mycorrhizal colonization } \\
\text { rate }(\%)\end{array}$ & Dry weight (g per plant) \\
\hline $\mathrm{CK}-\mathrm{AM}$ & $0.00 \pm 0.00 \mathrm{a}$ & $0.34 \pm 0.03 a$ \\
\hline $\mathrm{CK}+\mathrm{AM}$ & $97.33 \pm 1.33 d$ & $0.49 \pm 0.03 b$ \\
\hline $\mathrm{CK}+\mathrm{AM}+\mathrm{N} 1$ & $78.33 \pm 1.20 \mathrm{c}$ & $0.36 \pm 0.02 \mathrm{a}$ \\
\hline $\mathrm{CK}+\mathrm{AM}+\mathrm{N} 2$ & $71.67 \pm 1.76 b$ & $0.33 \pm 0.02 \mathrm{a}$ \\
\hline $\mathrm{A} 1-\mathrm{AM}$ & $0.00 \pm 0.00 \mathrm{a}$ & $0.25 \pm 0.01 \mathrm{a}$ \\
\hline $\mathrm{A} 1+\mathrm{AM}$ & $79.33 \pm 1.76 \mathrm{~d}$ & $0.25 \pm 0.02 \mathrm{a}$ \\
\hline $\mathrm{A} 1+\mathrm{AM}+\mathrm{N} 1$ & $58.67 \pm 2.03 c$ & $0.26 \pm 0.01 \mathrm{a}$ \\
\hline $\mathrm{A} 1+\mathrm{AM}+\mathrm{N} 2$ & $50.67 \pm 0.67 \mathrm{~b}$ & $0.27 \pm 0.01 \mathrm{a}$ \\
\hline $\mathrm{A} 2-\mathrm{AM}$ & $0.00 \pm 0.00 \mathrm{a}$ & $0.20 \pm 0.02 \mathrm{a}$ \\
\hline $\mathrm{A} 2+\mathrm{AM}$ & $63.33 \pm 1.67 \mathrm{~d}$ & $0.22 \pm 0.03 a$ \\
\hline $\mathrm{A} 2+\mathrm{AM}+\mathrm{N} 1$ & $51.33 \pm 0.67 \mathrm{c}$ & $0.20 \pm 0.01 \mathrm{a}$ \\
\hline $\mathrm{A} 2+\mathrm{AM}+\mathrm{N} 2$ & $44.00 \pm 1.00 \mathrm{~b}$ & $0.20 \pm 0.01 \mathrm{a}$ \\
\hline $\mathrm{AM}$ & $* * *$ & $* *$ \\
\hline A & $* * *$ & $* * *$ \\
\hline $\mathrm{AM}^{*} \mathrm{~A}$ & $* * *$ & $*$ \\
\hline N1 & * & $* * *$ \\
\hline $\mathrm{N} 1 * \mathrm{AM} * \mathrm{~A}$ & $*$ & * \\
\hline $\mathrm{N} 2$ & $* * *$ & $* *$ \\
\hline $\mathrm{N} 2 * \mathrm{AM} * \mathrm{~S}$ & $* *$ & $* *$ \\
\hline
\end{tabular}

${ }^{a}$ The different letters indicate significant differences between the treatments (Tukey's test $P<0.05$ ). ${ }^{* * *} P<0.001$, ${ }^{* *} P<0.01$, $* P<$ 0.05, N.S. $=$ not significant.

The dry weight of the L chinensis seedlings was significantly inhibited with the increasing the salt-alkali stress concentration, and alkali stress also further inhibited the dry weight $(P<$ 0.05 , Tables 1 and 2). The plants inoculated with the AMF had significantly higher seedling weights under both stress and non-stress conditions. The nitrogen treatments (N1 and N2) decreased the dry weight compared with the inoculated seedlings. The N1 and N2 treatments made no difference to the seedling dry weight under salt stress $(P>0.05)$. In addition, when alkali stress reached $100 \mathrm{mM}$, no significant change was observed among the four treatments (Table 2).

It is known that salt stress can affect plants, AMF, and their interactions. ${ }^{26,27}$ In the present study, the mycorrhizal colonization decreased with the increasing salt stress intensity, and decreased much more markedly under alkali stress (Table 2), indicating that salt-alkali stress inhibited the AMF growth. Some other reports have also supported this viewpoint. ${ }^{22}$ The main reason is that salt stress inhibits spore germination or hyphal growth. ${ }^{28}$ However, the much greater inhibition of alkali stress is perhaps due to high $\mathrm{pH}$ stress. Under such conditions, the plant root was subjected to much more damage, and the root also released many more chemical components into the soil, and then affected the mycorrhizal colonization. The specific reason requires further study. Our research also showed that nitrogen treatments could decrease the mycorrhizal colonization. One of the main reasons might be that the much higher concentration of nitrogen changed the function of the AMF. In addition, the inhibitory effect of $\mathrm{NH}_{4}{ }^{+}-\mathrm{N}$ was much stronger, and it might be that $\mathrm{NO}_{3}{ }^{-}-\mathrm{N}$ is more easily absorbed by $L$. chinensis, and the ammonium had a toxic effect to some extent, which also needs further research. 
Previous studies have demonstrated that plant growth can be inhibited under both salt and alkali stresses because of ionexcess effects. ${ }^{9,29}$ However, the plant must spend much more energy to cope with the high $\mathrm{pH}$ under alkali stress. Thus, the dry weight of L. chinensis under alkali stress was lower than that under salt stress. Moreover, the inoculated seedlings had higher dry weights under salt stress, showing that AMF could increase the salt tolerance of $L$. chinensis. Similar results have also been reported by others. ${ }^{30,31}$ However, alkali stress did not increase the seedling dry weights, which was also because of the high $\mathrm{pH}$ and much more damaging effects, and needs further research.

\section{Inorganic ion (cation and anion) content}

With the increasing intensity of the salt-alkali stress, the $\mathrm{Na}^{+}$ content in the shoot increased significantly $(P<0.05)$, and this effect was observed more markedly under alkali stress (Fig. 1A and B). AMF colonization decreased the $\mathrm{Na}^{+}$content under stress conditions, especially under higher concentration stress. When the salt concentration reached $200 \mathrm{mM}$, the $\mathrm{Na}^{+}$content of the seedlings inoculated with AMF was decreased by $18.1 \%$ and $18.8 \%$ compared with that of the non-inoculated seedlings under salt and alkali stresses. Both nitrogen treatments increased the $\mathrm{Na}^{+}$content at each salinity/alkalinity level in the AMF colonization treatments $(P<0.05)$, and the N1 and N2 treatments showed no significant differences, except for at $200 \mathrm{mM}$ salt stress. The $\mathrm{K}^{+}$content in the shoot decreased with increasing salt and alkali stresses, and these changes were much greater under alkali stress $(P<0.05)$. Except for at $100 \mathrm{mM}$ salt stress, AMF colonization increased the $\mathrm{K}^{+}$content under salt-alkali stress conditions. The nitrogen treatments decreased the $\mathrm{K}^{+}$content under salt-alkali stresses $(P<0.05)$, and the N1 and $\mathrm{N} 2$ treatments also showed no significant differences (Fig. 1C and D). In addition, AMF colonization did not affect the $\mathrm{Mg}^{2+}$ and $\mathrm{Ca}^{2+}$ content and, furthermore, the $\mathrm{N}$ treatments also had almost no influence on the $\mathrm{Mg}^{2+}$ and $\mathrm{Ca}^{2+}$ content (Fig. 1E$\mathrm{H})$.

With the increasing intensity of the salt stress, the $\mathrm{Cl}^{-}$ content in the shoot increased significantly, and AMF colonization decreased the $\mathrm{Cl}^{-}$content under salt stress $(P<0.05$; Fig. 2A). However, no significant change was observed in the $\mathrm{Cl}^{-}$ content under either alkali stress or AMF colonization with alkali stress $(P>0.05$; Fig. $2 \mathrm{~B})$. In addition, the nitrogen treatments increased the $\mathrm{Cl}^{-}$content in the L. chinensis seedlings. Under the alkali stress treatment, AMF colonization and nitrogen treatments both had no obvious significant effect on the $\mathrm{H}_{2} \mathrm{PO}_{4}{ }^{-}$and $\mathrm{SO}_{4}{ }^{2-}$ content $(P>0.05$; Fig. $2 \mathrm{D}$ and $\mathrm{F}$ ). Moreover, the $\mathrm{H}_{2} \mathrm{PO}_{4}{ }^{-}$and $\mathrm{SO}_{4}{ }^{2-}$ content only increased significantly at $100 \mathrm{mM}$ salt stress with the $\mathrm{N} 2$ treatment $(P<$ 0.05; Fig. 2C and E). The $\mathrm{NO}_{3}{ }^{-}$content in the shoot decreased with increasing salt and alkali stresses, and AMF colonization increased the $\mathrm{NO}_{3}{ }^{-}$content, but it only reached a significant level at CK and $200 \mathrm{mM}$ salt stress treatment $(P<0.05$; Fig. 2G). In addition, the $\mathrm{N}$ treatments have almost no influence on the $\mathrm{NO}_{3}{ }^{-}$content (Fig. $2 \mathrm{G}$ and $\mathrm{H}$ ).

Plants growing in salt-alkali soil generally suffer from two mainly distinct stresses: ionic stress and osmotic stress. $\mathrm{Na}^{+}$is one of the most dominating toxic ions in salinized and alkalinized soil. ${ }^{32}$ It can disrupt the structure of many macromolecules and their normal physiological metabolism. In addition, ionic imbalance is also a distinguishing feature caused by the influx of superfluous $\mathrm{Na}^{+} .^{33,34}$ The $\mathrm{Na}^{+}$ions enter the plant cells through a high-affinity $\mathrm{K}^{+}$transporter (HKT) and non-selective cation channels. ${ }^{35}$ Thus, for most plants living in salt-alkali environments, $\mathrm{Na}^{+}$often greatly accumulates in the vacuoles and also inhibits $\mathrm{K}^{+}$absorption. ${ }^{7}$ In our results, the $\mathrm{Na}^{+}$ concentration sharply increased and the $\mathrm{K}^{+}$concentration was simultaneously decreased under both salt and alkali stresses, with both the +AMF and -AMF treatments. However, the change was much greater under alkali stress, indicating that the high $\mathrm{pH}$ caused by alkali stress exerts much more damaging effects on the seedlings (higher $\mathrm{Na}^{+}$and lower $\mathrm{K}^{+}$), which rely on a transmembrane proton gradient. In addition, this result was in contradiction with observations of other halophytes, such as Kochia sieversiana and Chloris virgate, that are also widespread in the Songnen salt-alkali grassland in Northeastern China, ${ }^{29,36}$ and showed no competitive inhibition between the two ions in the two species, indicating that different plants may have distinct pathways for the absorption and transfer of $\mathrm{K}^{+}$and $\mathrm{Na}^{+}$, and need further research. Our results also showed that $\mathrm{Mg}^{2+}$ and $\mathrm{Ca}^{2+}$ increased under both salt stress and alkali stress, but their amounts were very low and their roles in ionic balance and osmotic adjustment were tiny.

It is widely recognized that $\mathrm{AM}$ symbiosis is a pivotal component in helping plants cope with adverse environments such as salt-alkali stress. ${ }^{37}$ It is evident from the present study that AM seedlings showed lower $\mathrm{Na}^{+}$and higher $\mathrm{K}^{+}$compared with the -AM plants, especially under the highest concentration of stress (200 mM, Fig. 1). These results show that the role of the mycorrhizal fungi in alleviating salt stress is mainly due to the inhibition of toxic $\mathrm{Na}^{+}$absorption and transportation. The lower levels of $\mathrm{Na}^{+}$in the AM seedlings may also be explained by the dilution effect because of plant growth enhancement. ${ }^{27}$ In addition, potassium is one of the most important essential elements for plant growth as it plays a key role in plant metabolism. The higher $\mathrm{K}^{+}$concentration and its direct effect of establishing a higher $\mathrm{K}^{+} / \mathrm{Na}^{+}$in the mycorrhizal plants under salt-alkali stress also relieved the negative impacts by the ionic balance of the cytoplasm or the $\mathrm{Na}$ efflux from the plant. ${ }^{15}$ Similar results have also been reported for other plants (with or without AM) under salt stress conditions, such as wheat and Trigonella foenum-graecum. ${ }^{38}$ Studies carried out by Giri et $a l .{ }^{15}$ have also indicated that the increased accumulation of $\mathrm{K}^{+}$reduced the translocation of $\mathrm{Na}^{+}$in the shoots of AMFcolonized acacia plants grown in saline soil.

Moreover, nitrogen deposition increased the $\mathrm{Na}^{+}$content and also decreased the $\mathrm{K}^{+}$content within the mycorrhizal inoculation treatments of the L. chinensis seedlings, especially under the N2 treatment (Fig. 1). The main reason for this finding is that excessive nitrogen in the soil induces a nutrient imbalance and also changes the distribution and transportation of ions. The ammonium may have a toxic effect to some extent, and the specific mechanism needs further research. The above results also clearly show that nitrogen deposition (different 


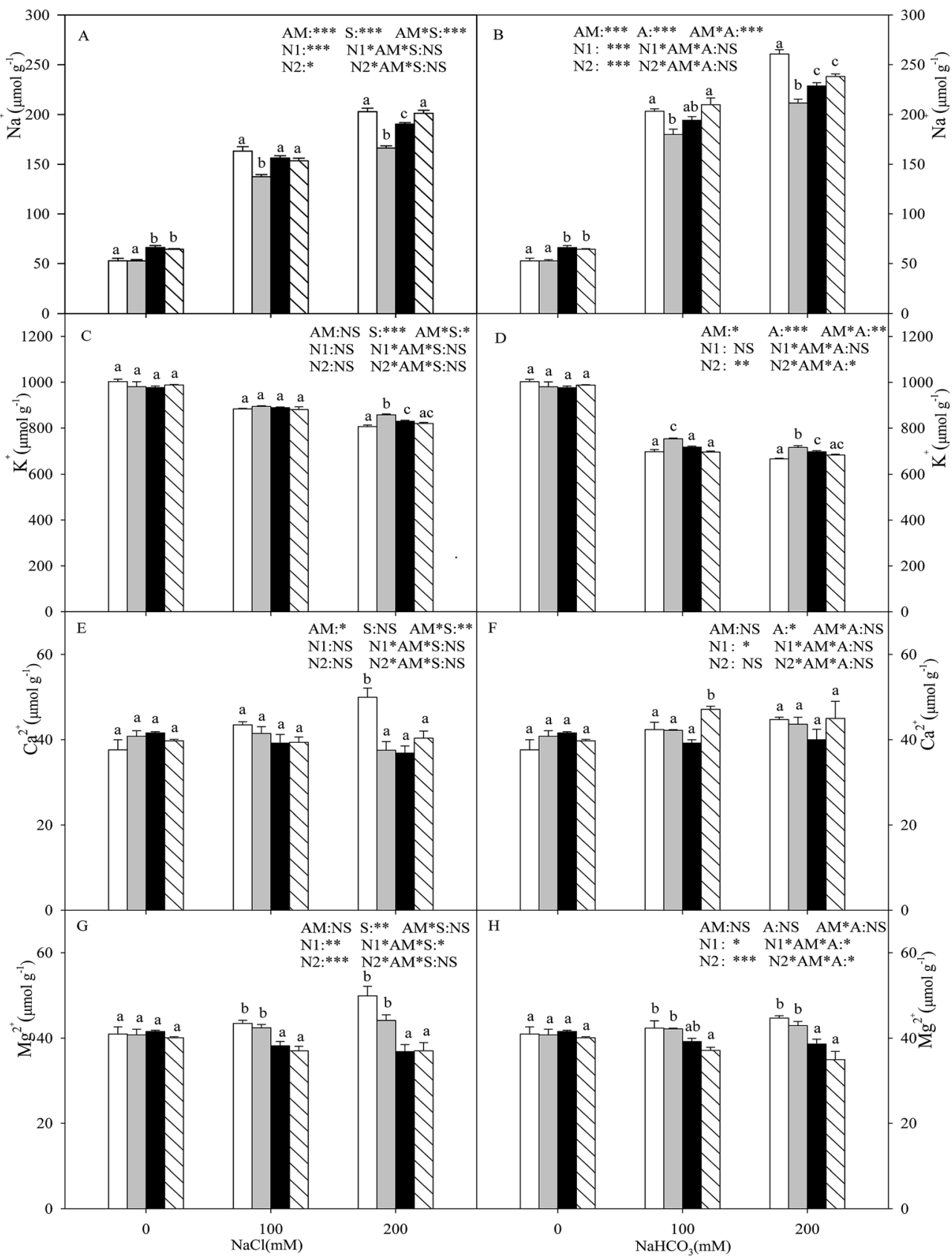

Fig. $1 \mathrm{Na}^{+}(\mathrm{A}$ and $\mathrm{B}), \mathrm{K}^{+}(\mathrm{C}$ and $\mathrm{D}), \mathrm{Ca}^{2+}(\mathrm{E}$ and $\mathrm{F})$, and $\mathrm{Mg}^{2+}(\mathrm{G}$ and $\mathrm{H})$ content in Leymus chinensis seedlings [non $\mathrm{AM}(\square), \mathrm{AM}(\square), \mathrm{AM}+\mathrm{N} 1(\square)$, $A M+N 2($ ) under nitrogen deposition, salinity $(A, C, E$, and G), and alkalinity $(B, D, F$, and H) conditions. The bars represent mean $\pm S . E$. ( $n=4)$. The different letters indicate significant differences between the treatments (Tukey's test $P<0.05$ ). $* * * P<0.001, * * P<0.01, * P<0.05, \mathrm{NS}=$ not significant.

concentrations of $\mathrm{NH}_{4}{ }^{+} / \mathrm{NO}_{3}{ }^{-}$) decreased the salt-alkali tolerance of the $L$. chinensis seedlings by reducing the suitability of the colonization.

Ionic imbalance within plants has been reported to be mainly caused by the influx of superfluous $\mathrm{Na}^{+} \cdot{ }^{33}$ Most plants always accumulate the main inorganic anions, such as $\mathrm{Cl}^{-}$, at this point to cope with adverse environments. In our study, $\mathrm{Cl}^{-}$ and $\mathrm{SO}_{4}{ }^{2-}$ were accumulated in the $L$. chinensis seedlings under salt stress. However, all of the anions showed a decreasing trend under alkali stress (Fig. 2A). Our results verified that salt stress and alkali stress had different physiological effects on the plants, and the high $\mathrm{pH}$ might inhibit the absorption of inorganic anions such as $\mathrm{Cl}^{-}, \mathrm{NO}_{3}{ }^{-}$, and $\mathrm{SO}_{4}{ }^{2-}$. Similar results were also reported for other plants (both crops and grasses), such as the tomato, ${ }^{39}$ seabuckthorn ${ }^{40}$, and Lathyrus quinquenervius. ${ }^{11}$

In general, superfluous $\mathrm{Cl}^{-}$can also be toxic to plant growth in saline areas. ${ }^{41}$ This problem can also be resolved by using arbuscular mycorrhiza to some extent, which can decrease the $\mathrm{Cl}^{-}$uptake. ${ }^{42}$ In our results, AMF colonization decreased the $\mathrm{Cl}^{-}$ content under salt stress, which is consistent with the previous 


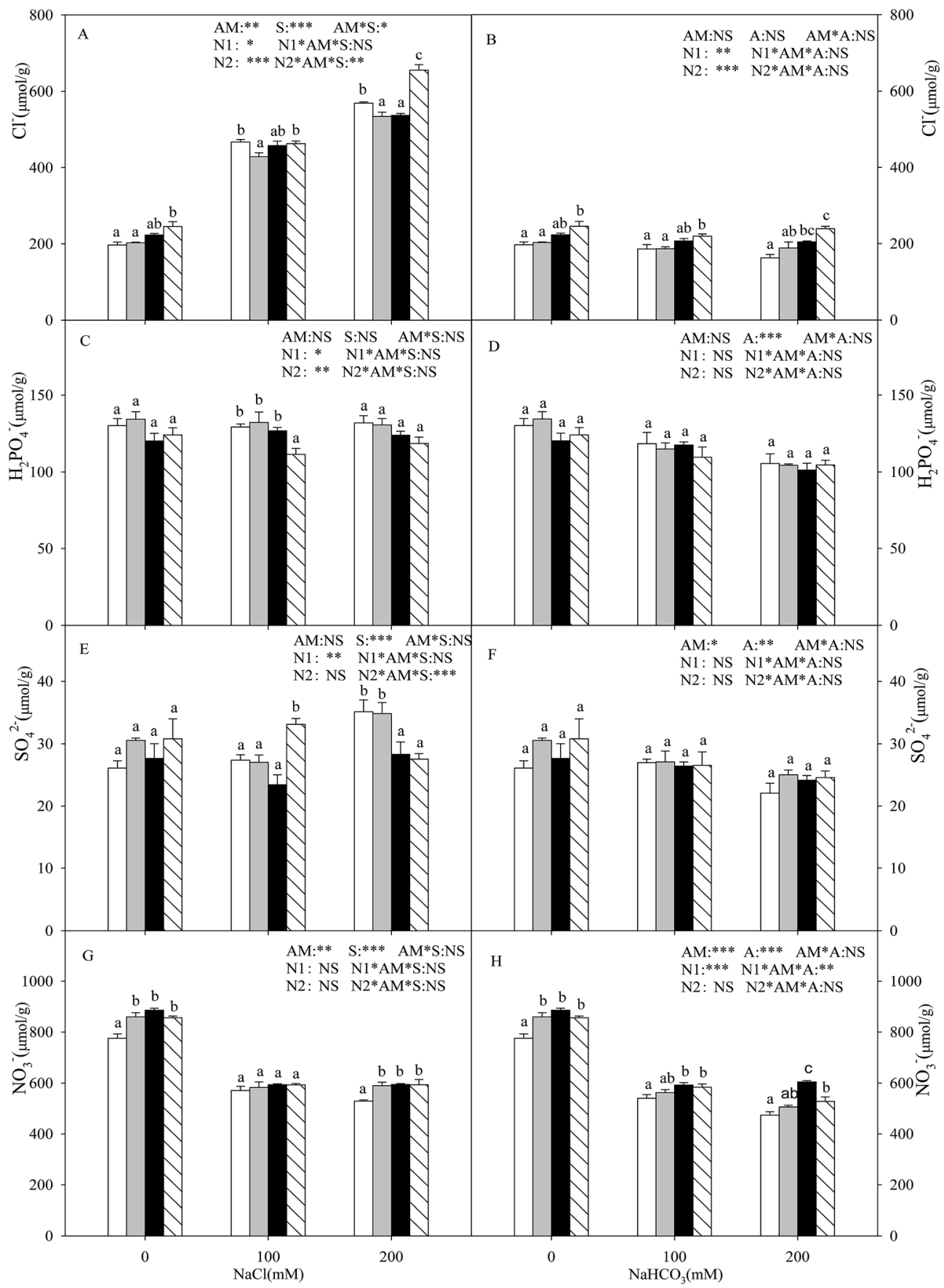

Fig. $2 \mathrm{Cl}^{-}(\mathrm{A}$ and $\mathrm{B}), \mathrm{H}_{2} \mathrm{PO}_{4}^{-}(\mathrm{C}$ and $\mathrm{D}), \mathrm{SO}_{4}{ }^{2-}(\mathrm{E}$ and $\mathrm{F})$, and $\mathrm{NO}_{3}{ }^{-}(\mathrm{G}$ and $\mathrm{H})$ content in Leymus chinensis seedlings [non $\mathrm{AM}(\square), \mathrm{AM}(\square), \mathrm{AM}+\mathrm{N} 1$ $(\mathbf{\square}), A M+N 2(\mathbb{E})]$ under nitrogen deposition, salinity (A, C, E, and G), and alkalinity (B, D, F, and H) conditions. The bars represent mean \pm S.E. ( $n=$ 4). The different letters indicate the significant differences between the treatments (Tukey's test $P<0.05$ ). ${ }^{* * *} P<0.001, * * P<0.01, * P<0.05$, NS $=$ not significant.

report on lettuce and onions, ${ }^{43}$ but there was no significant difference between the $-\mathrm{AM}$ and mycorrhizal inoculation treatments in L. chinensis seedlings under alkali stress because of the severe influence of the high $\mathrm{pH}$. In addition, the result was in contradiction with observations reported for citrus plants, spring wheat, and winter barley. ${ }^{44,45}$ They found that the $\mathrm{Cl}^{-}$content increased due to the mycorrhizal colonization, and the main reason is perhaps the carbon drain imposed by the mycorrhizal hyphae on plants, and then the enhancement of the translocation of $\mathrm{Cl}^{-}$from the saline soil. The differences in the plant species may be a reason for these differences and for their specific causes, both of which should be further investigated. Moreover, similar changes were observed for $\mathrm{Cl}^{-}$and $\mathrm{Na}^{+}$ when the L. chinensis seedlings were inoculated with mycorrhizal, further illustrating the negative impact of nitrogen deposition, especially the ammonium nitrogen. Interestingly, $L$. 
chinensis seedlings can also maintain constant ionic balance under nitrogen treatment.

\section{Organic solute content}

With the increasing intensity of the salt-alkali stress, the proline content in the shoots of the L. chinensis seedlings increased significantly, and this effect was observed more markedly under salt stress $(P<0.05$, Fig. 3A and B). AMF colonization decreased the proline content under stress conditions, especially under the highest concentration stress (200 mM), where the proline content decreased by $65.8 \%$. The application of either nitrogen treatment increased the proline content at each salinity/alkalinity level (Fig. 3A and B). The soluble sugar content showed a similar tendency to the proline (Fig. $3 \mathrm{C}$ and D). In addition, AMF colonization only decreased the soluble sugar content to $19.6 \%$ at $200 \mathrm{mM}$ alkali stress. The $\mathrm{N}$ treatments had no influence on the soluble sugar content of the inoculated seedlings. The soluble sugar content only increased at alkali stress under the $\mathrm{N} 2$ treatment. AM colonization did not affect the MDA content under salt and alkali stresses (Fig. 3E and $\mathrm{F}$ ). The $\mathrm{N}$ treatments increased the MDA content, much more markedly with the $\mathrm{N} 2$ treatment.

Malic acid, citric acid, acetate acid, and oxalate acid were detected in the shoots of the L. chinensis seedlings under salt and alkali stresses (Fig. 4). The citric acid content increased under alkali stress (Fig. 4B), and AMF colonization and $\mathrm{N}$ treatments did not affect the citric acid content under saltalkali stress. The malic acid content showed a similar tendency to that of citric acid. AMF colonization decreased the malic acid content by $31.5 \%$ under $200 \mathrm{mM}$ alkali stress, but did not affect the content at other stress concentrations (Fig. 4D and E). In addition, the $\mathrm{N}$ treatments have almost no influence on the malic acid content. AMF colonization also decreased the acetate acid content according to Fig. $4 \mathrm{E}$ and F. However, unlike these

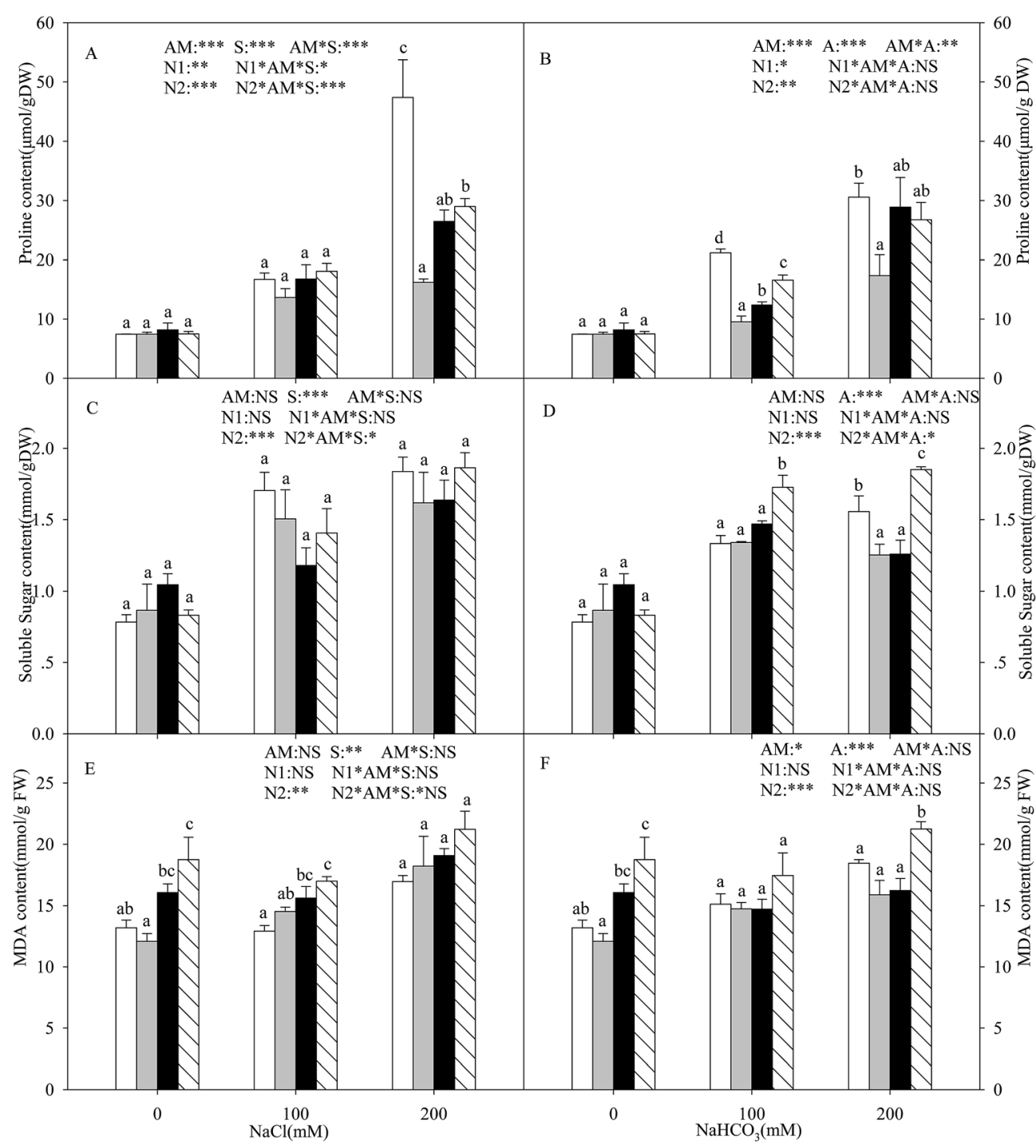

Fig. 3 Proline (A and B), soluble sugar (C and D), and MDA (E and F) content in Leymus chinensis seedlings $[$ non $A M(\square), A M(\square), A M+N 1(\square), A M+$ N2 ( $)$ ] under nitrogen deposition, salinity $(A, C, E$, and $G)$, and alkalinity $(B, D, F$, and $H)$ conditions. The different letters indicate significant differences between the treatments (Tukey's test $P<0.05$ ). ${ }^{* * *} P<0.001, * * P<0.01, * P<0.05$, NS = not significant. 


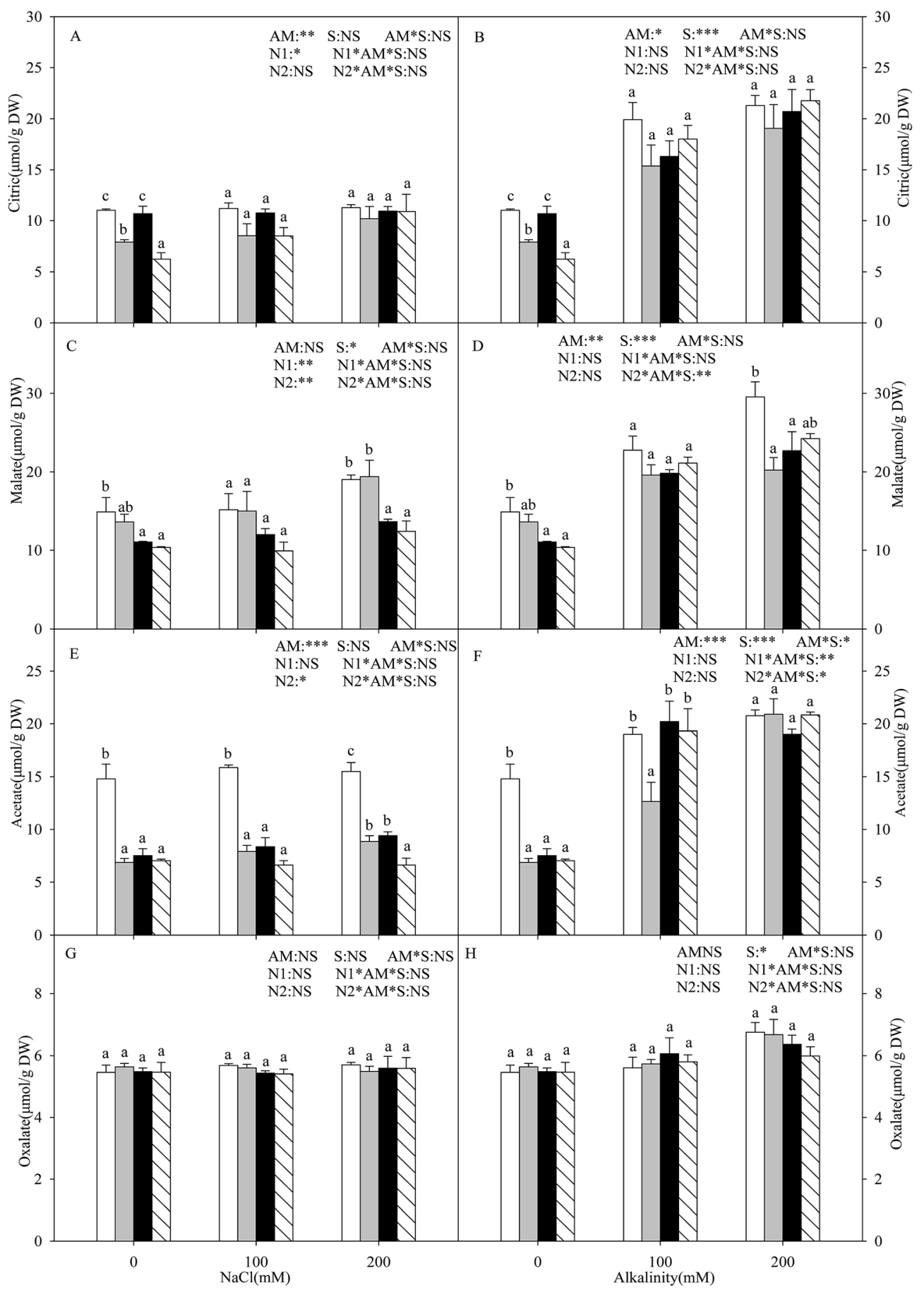

Fig. 4 Citric acid (A and B), malic acid ( $C$ and D), acetic acid ( $E$ and $F$ ), and oxalic acid ( $G$ and $H$ ) content in Leymus chinensis seedlings [non AM ( $\square$ ), $A M(\square), A M+N 1(\square), A M+N 2(\mathbb{a})]$ under nitrogen deposition, salinity $(A, C, E$, and $G)$, and alkalinity $(B, D, F$, and $H)$ conditions. The different letters indicate significant differences between the treatments (Tukey's test $P<0.05$ ). ${ }^{* * *} P<0.001, * * P<0.01, * P<0.05$, NS $=$ not significant.

three organic acid compositions, no change was observed in the oxalate acid content under both the AM or $\mathrm{N}$ treatments (Fig. 4G and $\mathrm{H}$ ).

In salt-alkali environments, plants must face the negative impact of the lower water potential of the soil, which makes it difficult for the plants to acquire adequate water from the surrounding soil. Several organic solutes, such as proline, soluble sugar, and MDA, are accumulated under these conditions. In general, proline accumulation is thought to be an adaptive feature under salt-alkali stress in both AM and nonAM plants. ${ }^{46}$ Our results showed that the accumulation of proline in the L. chinensis seedlings increased with increasing salt-alkaline concentration (Fig. 3A and B). Moreover, the proline content was detected to decrease in the seedlings with 
AMF inoculation. This differed to most previous reports, which found that AMF colonization could increase the proline content in plants such as soybean and wheat. ${ }^{46}$ However, similar results were found for Vicia faba by Rabie and Almadini. ${ }^{47}$ The possible reason is that the proline content can also be used for measuring the degree of plants that were injured, indicating that AMF colonization alleviates salt-alkali stress on the $L$. chinensis seedlings. The nitrogen deposition results also prove this viewpoint.

Organic acids also played a potential role as cell osmolytes in the osmotic adjustment. ${ }^{48}$ In our study, we clearly found that salt stress did not affect the amounts of four organic acids (malic acid, citric acid, acetate acid, and oxalate acid), but alkali stress significantly enhanced them, indicating that organic acid accumulation is a specific response to high $\mathrm{pH}$ stress. Under alkali stress, superfluous $\mathrm{Na}^{+}$was accumulated, but the $\mathrm{Cl}^{-}$ content had no significant change. Thus, we consider that the accumulation of organic acids not only played an important osmotic role but also buffered excess toxic cations and maintained ionic balance. Similar viewpoints have also been reported by others. ${ }^{9,11}$ In addition, we also found that AMF colonization did not affect the organic acid content, except for acetate acid, but decreased most of them under alkali stress. Combined with the $\mathrm{Na}^{+}$and $\mathrm{Cl}^{-}$results as described above, we conclude that there exists a correlation between the $\mathrm{Na}^{+}$and organic acid content, and that $L$. chinensis seedlings can maintain ionic balance under both AM and non-AM conditions. In addition, the organic acid content showed an increasing trend in the AM seedlings that underwent the $\mathrm{N}$ treatments to some extent, especially the N2 treatment. The main reason for this finding is that excessive nitrogen in the soil causes a negative effect on the AMF, and the host plant needs to synthesize much more organic acid to resist the stress conditions, which needs further research.

\section{Conclusion}

In brief, the results of the present investigation show that salt stress and alkali stress differ greatly and the physiological adaptive strategy of $L$. chinensis seedlings to the two stresses is also different. AMF colonization can protect the seedlings against salt-alkali stress and nitrogen deposition by adjusting the osmotic and ion balance (by changing the inorganic cationanion and organic solute content). In addition, excessive nitrogen exerts negative effects on the mycorrhizal colonization and the salt-alkali tolerance of $L$. chinensis seedlings. Therefore, AMF inoculation in L. chinensis seedlings could serve as a useful tool for alleviating salinity and alkalinity stress, and could be further applied to a practice such as restoring and reestablishing deteriorated salt-alkali grasslands, as found in northeastern China. In addition, our study also provides an important theoretical basis for the responses of Leymus chinensis-AMF symbionts to nitrogen deposition.

\section{Conflicts of interest}

There are no conflicts to declare.

\section{Acknowledgements}

The research was supported by the National Natural Science Foundation of China (31502013), and the Natural Science Foundation of Heilongjiang Province (C2015060). We thank Shuang Tao and Shuai Shao for their help in the laboratory.

\section{References}

1 M. Kanakidou, S. Myriokefalitakis, N. Daskalakis, G. Fanourgakis, A. Nenes, A. R. Baker, K. Tsigaridis and N. Mihalopoulos, J. Atmos. Sci., 2016, 73(5), 2039-2047.

2 M. A. Sutton and A. Bleeker, Nature, 2013, 494(7438), 435437.

3 A. F. Bouwman, D. P. Van Vuuren, R. G. Derwent and M. Posch, Water, Air, Soil Pollut., 2002, 141(1), 349-382.

4 W. D. Bowman, C. C. Cleveland, Ĺ. Halada, J. Hreško and J. S. Baron, Nat. Geosci., 2008, 1(11), 767-770.

5 C. M. Jiang, W. T. Yu, Q. Ma, Y. G. Xu, H. Zou, S. C. Zhang and W. P. Sheng, Environ. Pollut., 2013, 182, 430-436.

6 H. F. Fan, C. X. Du and S. R. Guo, Environ. Exp. Bot., 2013, 86, 52-59.

7 R. Munns, Plant, Cell Environ., 2002, 25(2), 239-250.

8 A. K. Parida and A. B. Das, Ecotoxicol. Environ. Saf., 2005, 60(3), 324-349.

9 C. W. Yang, P. Wang, C. Y. Li, D. C. Shi and D. L. Wang, Photosynthetica, 2008, 46(1), 107-114.

10 R. Guo, L. X. Shi and Y. F. Yang, Soil Sci. Plant Nutr., 2009, 55(5), 667-679.

11 J. T. Zhang and C. S. Mu, Soil Sci. Plant Nutr., 2009, 55(5), 685-697.

12 N. Aliasgharzadeh, S. N. Rastin, H. Towfighi and A. Alizadeh, Mycorrhiza, 2001, 11(3), 119-122.

13 G. N. Al-Karaki, Mycorrhiza, 2000, 10(2), 51-54.

14 H. R. Asghari, P. Marschner, S. E. Smith and F. A. Smith, Plant Soil, 2005, 273(1-2), 245-256.

15 B. Giri, R. Kapoor and K. G. Mukerji, Microb. Ecol., 2007, 54(4), 753-760.

16 Z. Q. He, C. X. He, Z. B. Zhang, Z. R. Zuo and H. S. Wang, Colloids Surf., B, 2007, 59(2), 128-133.

17 M. Echeverria, A. A. Scambato, A. I. Sannazzaro, S. Maiale, O. A. Ruiz and A. B. Menéndez, Mycorrhiza, 2008, 18(6-7), 317-329.

18 J. X. Lin, Y. N. Wang, S. N. Sun, C. S. Mu and X. F. Yan, Sci. Total Environ., 2017, 576, 234-241.

19 G. S. Liu and D. M. Qi, Acta Prataculturae Sinica, 2004, 13, 611.

20 Y. F. Yang, G. C. Liu and B. T. Zhang, Acta Bot. Sin., 1995, 37, 147-153.

21 J. M. Phillips and D. S. Hayman, Trans. Br. Mycol. Soc., 1970, 55(1), 158-163.

22 Q. S. Wu, Y. N. Zou and X. H. He, Acta Physiol. Plant., 2010, 32, 297-304.

23 S. D. Bao, Analysis Methods for Soil and Agriculture Chemistry, China Agr. Press, Beijing, 1981.

24 G. L. Zhu, X. W. Deng and W. N. Zuo, Plant Physiol., 1983, 1, 35-37. 
25 C. M. Greive and S. R. Grattan, Plant Soil, 1983, 70, 303-307. 26 A. A. Murkute, S. Sharma and S. K. Singh, Hortic. Sci., 2006, 33, 70-76.

27 H. Evelin, R. Kapoor and B. Giri, Ann. Bot., 2009, 104, 12631280.

28 R. Hajiboland, A. Aliasgharzadeh, S. F. Laiegh and C. Poschenrieder, Plant Soil, 2010, 331, 313-327.

29 C. W. Yang, W. Q. Guo and D. C. Shi, J. Agron., 2010, 102(4), 1081-1089.

30 G. Feng, F. S. Zhang, X. L. Li, C. Y. Tian, C. Tang and Z. Rengel, Mycorrhiza, 2002, 12, 185-190.

31 F. Jahromi, R. Aroca, R. Porcel and J. M. Ruiz-Lozano, Microb. Ecol., 2008, 55, 45-53.

32 E. Blumwald, Curr. Opin. Cell Biol., 2000, 12(4), 431-434.

33 R. Munns and M. Tester, Annu. Rev. Plant Biol., 2008, 59, 651-681.

34 X. Wang, S. Geng, Y. J. Ri, D. Cao, J. Liu, D. Shi and C. Yang, Sci. Hortic., 2011, 130(1), 248-255.

35 J. K. Zhu, Curr. Opin. Cell Biol., 2003, 6, 441-445.

36 C. W. Yang, J. N. Chong, C. N. Kim, D. C. Shi and D. L. Wang, Plant Soil, 2007, 294, 263-276.

37 R. Porcel, R. Aroca and J. M. Ruiz-Lozano, Agron. Sustainable Dev., 2012, 32, 181-200.
38 H. Evelin, B. Giri and R. Kapoor, Mycorrhiza, 2013, 23(1), 7186.

39 X. P. Wang, S. J. Geng, Y. J. Ri, D. H. Cao, J. Liu, D. C. Shi and C. W. Yang, Sci. Hortic., 2011, 130, 248-255.

40 W. C. Chen, P. J. Cui, H. Y. Sun, W. Q. Guo, C. W. Yang, H. Jin, B. Fang and D. C. Shi, Ind. Crops Prod., 2009, 30(3), 351-358.

41 G. H. Xu, H. Magen, J. Tarchitzky and U. Kafkafi, Adv. Agron., 1999, 68, 97-150.

42 P. Zuccarini and P. Okurowska, J. Plant Nutr., 2008, 31(3), 497-513.

43 I. C. Cantrell and R. G. Linderman, Plant Soil, 2001, 233, 269281.

44 J. G. Bulwada, D. P. Stribley and P. B. Tinker, New Phytol., 1983, 93, 217-225.

45 J. H. Graham and J. P. Syversten, New Phytol., 1984, 97, 277284.

46 M. Sharifi, M. Ghorbanli and H. Ebrahimzdeh, J. Plant Physiol., 2007, 164(9), 1144-1151.

47 G. H. Rabie and A. M. Almadini, Afr. J. Biotechnol., 2005, 4, 210-222.

48 J. X. Lin, C. S. Mu, Y. Wang and X. Li, J. Anim. Plant Sci., 2014, 24(3), 904-912. 